\title{
Comparison of Marital Commitment and Relationship Quality between Fertile- and Infertile Couples
}

\section{ART ICLE INF O}

\section{Article Type}

Descriptive Study

\section{Authors}

Shahhosseini Tazik S. ${ }^{* 1} M A$,

Taheri N. ${ }^{1} M A$

Sayyadi M. ${ }^{1} M A$

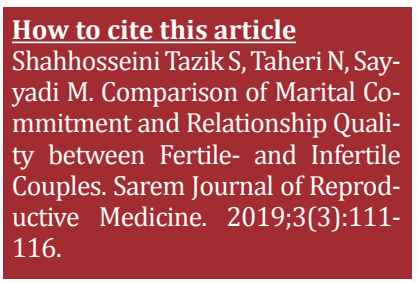

${ }^{1}$ Educational Psychology and Consultation Department, Psychology \& Educational Faculty Sciences, University of Tehran, Tehran, Iran

\section{*Correspondence}

Address: Kavian University, Kosar 13, kosar Boulevard, Vakil Abad Boulevard, Mashhad, Khorasan Razavi, Iran. Postal Code: 9178647743 Phone: +98 (51) 38816393 Fax: +98 (51) 38827895 s.shahhosseini.psy@gmail.com

\section{Article History}

Received: June 7, 2018

Accepted: April 14, 2019

ePublished: July 6, 2019

\begin{abstract}
A B S T R A C T
Aims Infertility is one of the main problems in a marriage, which can have various psychological consequences, including the inability to establish quality relationship between the couples and the instability of their marital commitment. The aim of this study was to investigate the relationship between marital commitment and relationship quality of fertile couples compared with infertile couples.

Instrument \& Methods In this descriptive cohort study conducted between 2015 and 2016, 170 fertile $(\mathrm{N}=89)$ and infertile $(\mathrm{N}=81)$ men and women (infertile) referred to Sarem Hospital were selected, using available sampling. The instrument of study was marital commitment questionnaire and couples' relationship quality questionnaire. The data were analyzed by SPSS 19, using the Pearson correlation coefficient and Student t-test.

Findings There was a significant difference in the quality of relationship and all its subscales except the attention paid to the spouse as well as only in the subscale of personal commitment among the subscales of marital commitment of fertile and infertile couples $(\mathrm{p}<0.05)$. In both groups, there was a positive and significant correlation between marital commitment and quality of life, which was stronger in the fertile group $(r=0.27)(r=0.28)$ than in infertile group $(\mathrm{r}=0.18 ; \mathrm{p}<0.05)$.

Conclusion Infertility decreases the level of couples' personal commitment to marital life and can undermine the quality of their relationship.
\end{abstract}

\section{Keywords Marriage; Commitment; Marital Relationship; Infertility}

\section{I T A T I O N L I N K S}

[1] Psychosocial adjustment in infertility: A comparison study of infertile couples, couples undergoing assisted reproductive ... [2] Examining congruence between partners' perceived infertility-related stress and its relationship to marital ... [3] Lesbian sexuality/female sexuality: Rethinking 'lesbian bed ... [4] Understanding the emotional aspects of infertility: Implications for nursing ... [5] Investigation of the prevalence of depression and factors affecting it in infertile women admitted in Mashhad's ... [6] Evaluation of marital and sexual interactions of Polish ... [7] Current practices and controversies in assisted ... [8] On the relationship between sexual satisfaction and marital commitment among couples in Shahreza City, central part ... [9] Couples in ... [10] The threefold cord: Marital commitment in religious ... [11] The tripartite nature of marital commitment: Personal, moral, and structural reasons to stay ... [12] The effectiveness of educating reality therapy on couples' marital commitment in ... [13] Reconciling divergent perspectives: Judith Wallerstein, quantitative family research, and children of ... [14] Gender differences in how men and women who are referred for IVF cope with infertility ... [15] Family therapy: Concepts and ... [16] Commitment and attachment dimensions: Contributions to adult attachment ... [17] Commitment to one's spouse as a predictor of marital quality among older ... [18] The effectiveness of schema-therapy on promoting marital commitment and couples' ... [19] Communication, conflict, and commitment: Insights on the foundations of relationship success from a national ... [20] Clinical gynecologic endocrinology and ... [21] Developing quality of life in infertile couples questionnaire and measuring its psychometric ... [22] Sexual and marital ... [23] Codifying and examine psychometrics properties of marital sexual function ... [24] Exploring relationships among communication, sexual satisfaction ... [25] On the relationship among parenting styles, attachment styles and marital ... [26] The conceptualization of marital commitment: An integrative ... [27] The effect of changing attitudes to marriage on... [28] The effect of couple's relationship training course ... 
نابارورى جنين تعريف شده است كه يس از يك سال نزديكى بدون

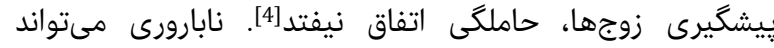

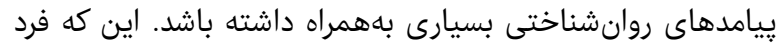

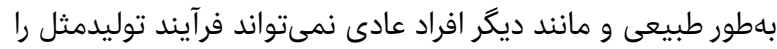

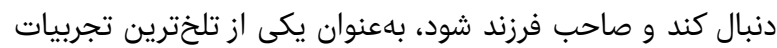

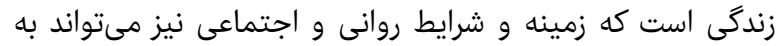

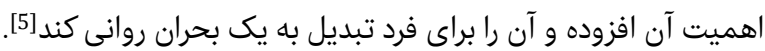

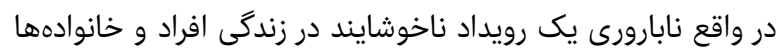

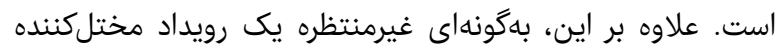

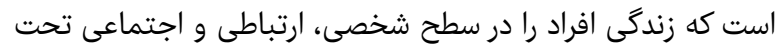

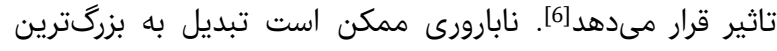

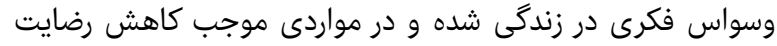

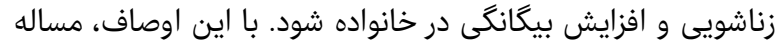

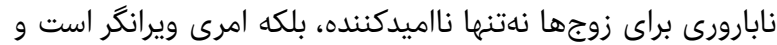

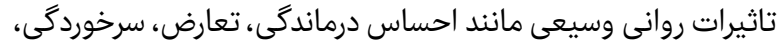

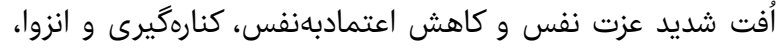

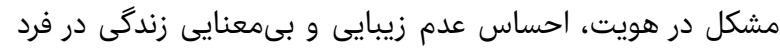

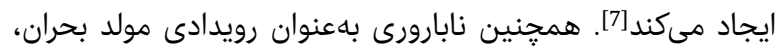

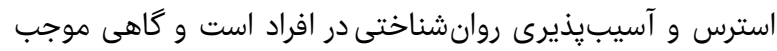

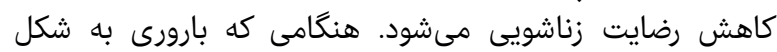

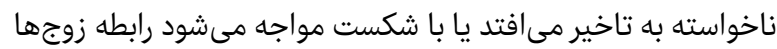

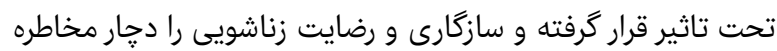

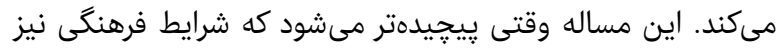

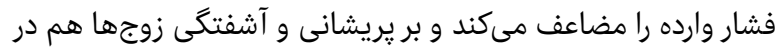

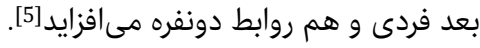

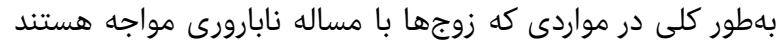

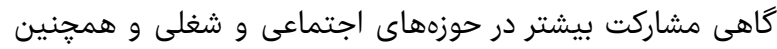

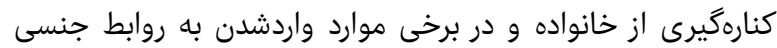

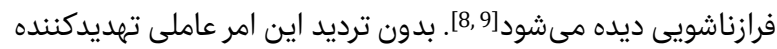

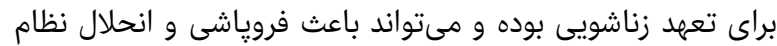

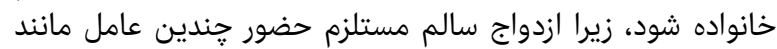

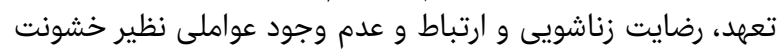

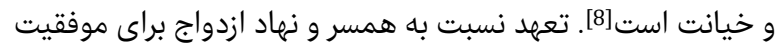

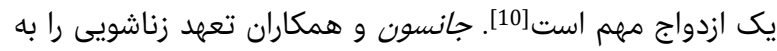

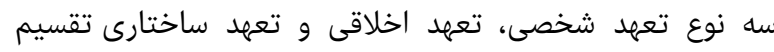

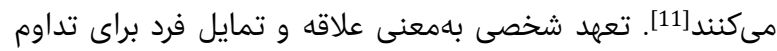

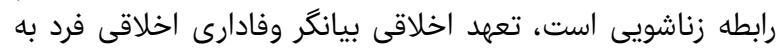

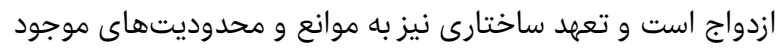
در ترك رابطه زناشويى و احساس اجبار بارئ تداوم آنارئ آن رابطه يا ترس از

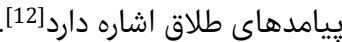

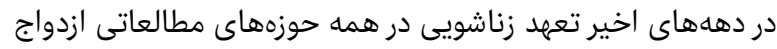

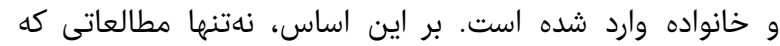

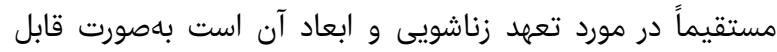

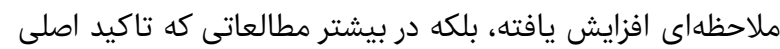

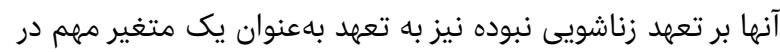

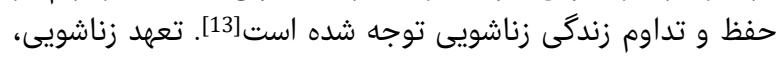

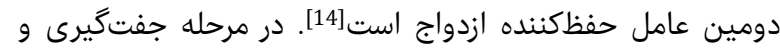

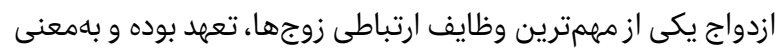

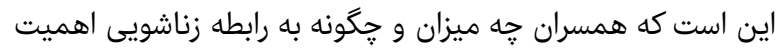

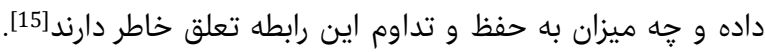

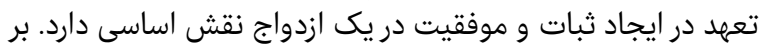

مقايسه تعهد زناشويى و كيفيت ارتباط بين

\section{زوجهاى بارور و نابارور}

MA " سعيد شاهحسينى تازيك

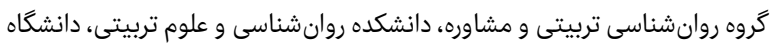
تهران، تهران، ايران

MA نجمه طاهرى ترون ايران

كروه روان شناسى تربيتى و مشاوره، دانشكده روانشناسى و علوم تربيتى، دانشكاه تهران، تهران، ايران

MA معصومه صيادى تران، ايران

كروه روانشناسى تربيتى و مشاوره، دانشكده روانشان شناسى و علوم تربيتى، دانشكاه تهران، تهران، ايران

جكيده

اهداف: نابارورى يكى از مشكلات اساسى زندگى زناشويى است كه ميتواندي

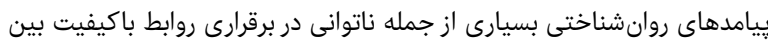

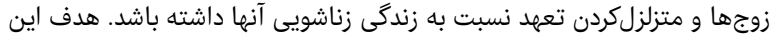

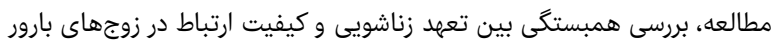
در مقايسه با زوجهاى نابارور بود.

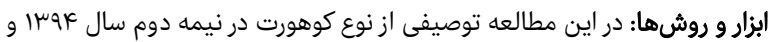

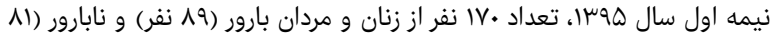

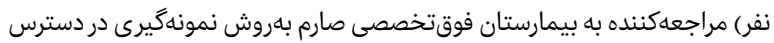

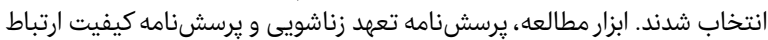

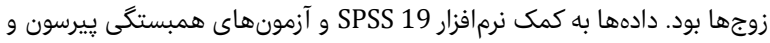

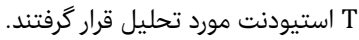

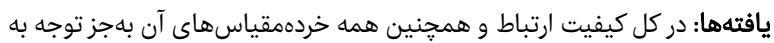

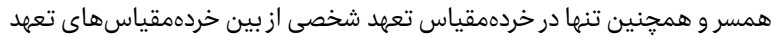

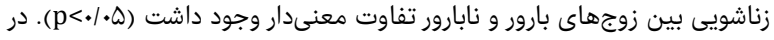

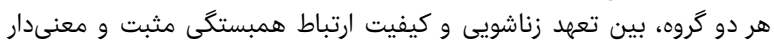

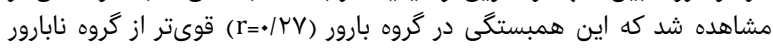

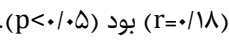

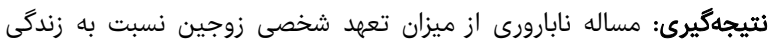

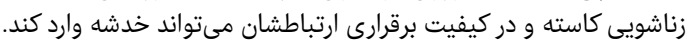
كليدوازمها: ازدواج، تعهد، رابطه زناشويى، نابارورى

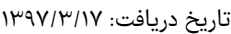

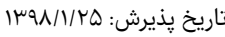

"نويسنده مسئول: S.shahhosseini.psy@gmail.com

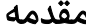

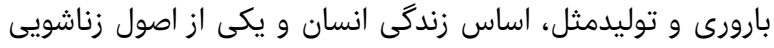

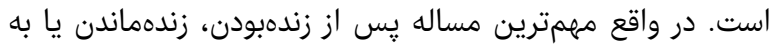

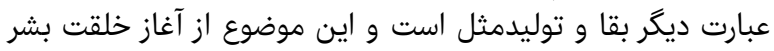

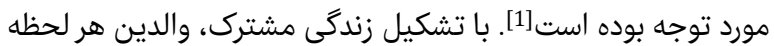

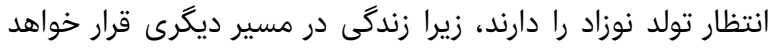

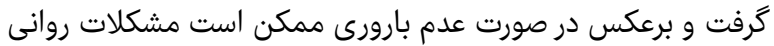

زيادى براى زن و مرد به وجود درد بيه بيايد [2].

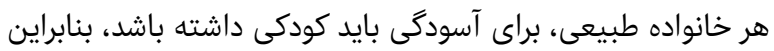

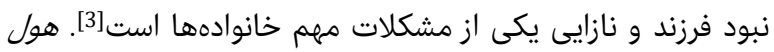

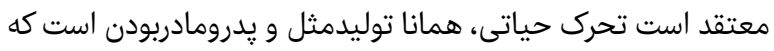

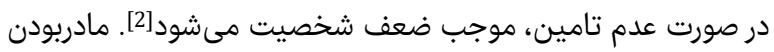

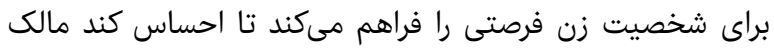

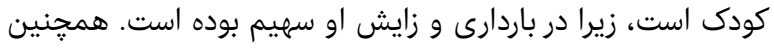
يدربودن، براى مرد فرصتى ايجاد مىكند تا آرزوى زن را درا در توليد فرزند

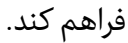




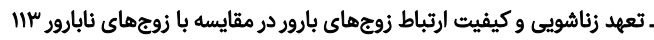

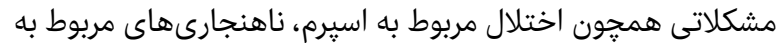

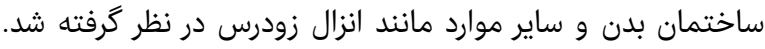

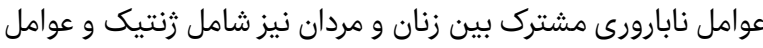

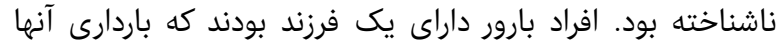

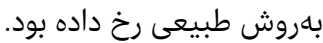

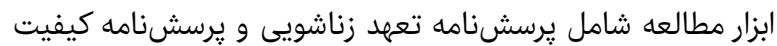

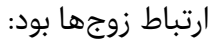

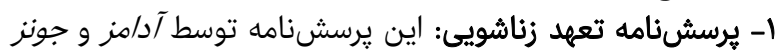

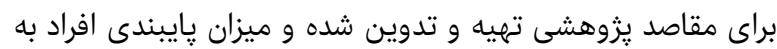

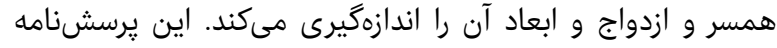
داراى

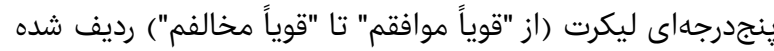

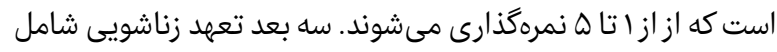

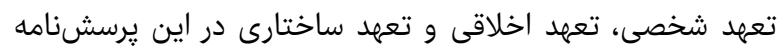

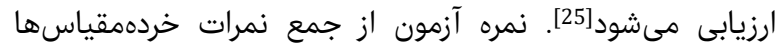

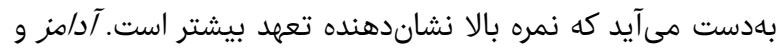

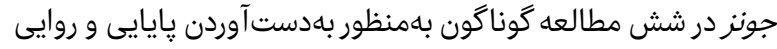

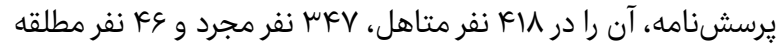

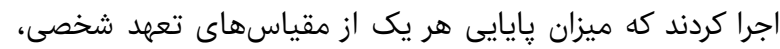

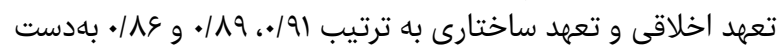

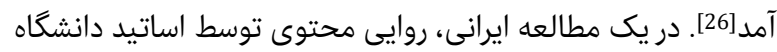

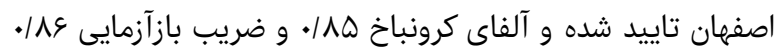

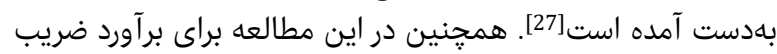

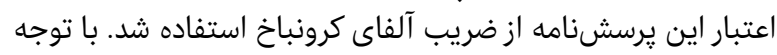

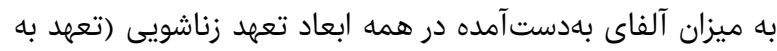

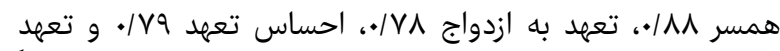

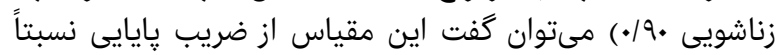

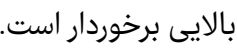

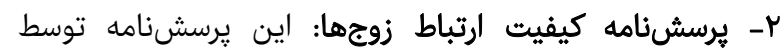

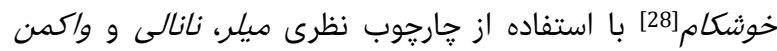

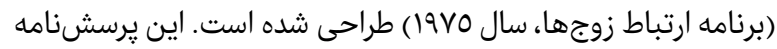

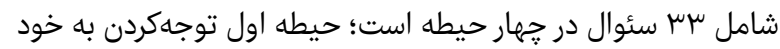

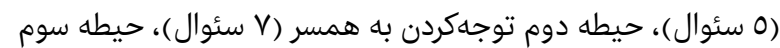

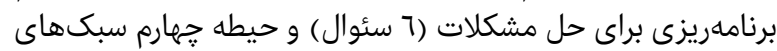

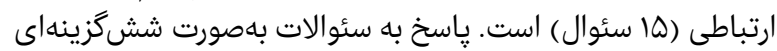

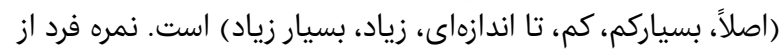

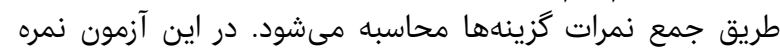

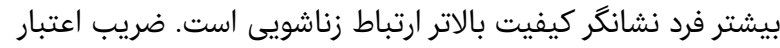

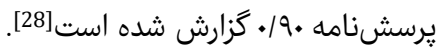

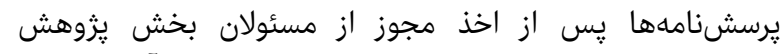

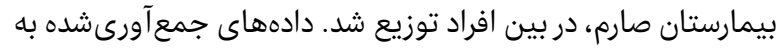

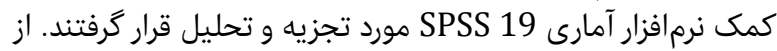

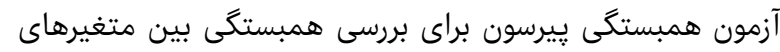

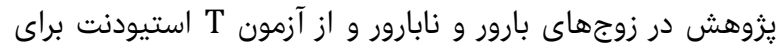

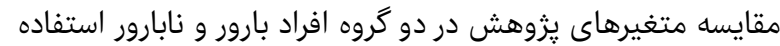

\section{يافتهها}

در كل كيفيت ارتباط و همجنين بيشتر خردهمقياسهاى آن از جمله

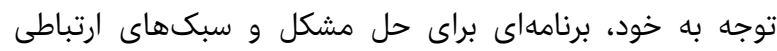

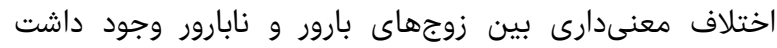

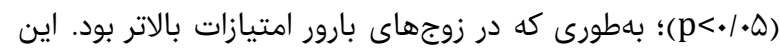

اين اساس هر گونه رابطه بدون تعهد، سطحى و بدون سمتوسو

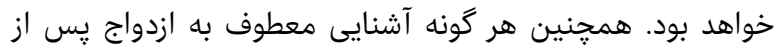

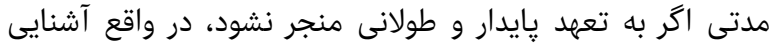

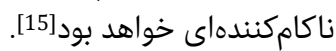

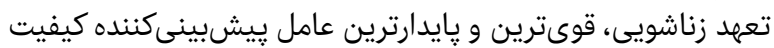

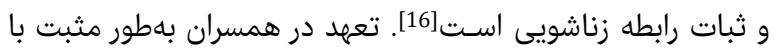

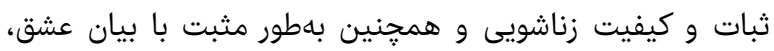

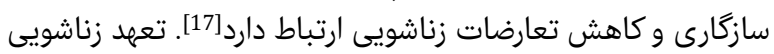

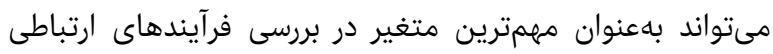

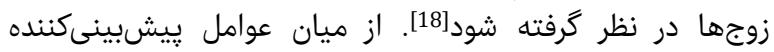

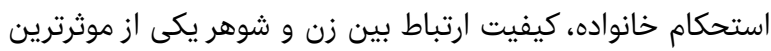

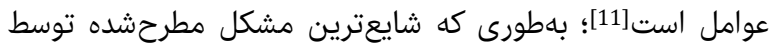

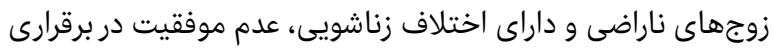

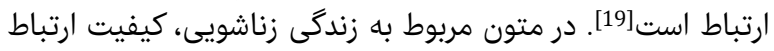

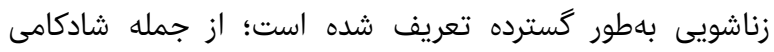

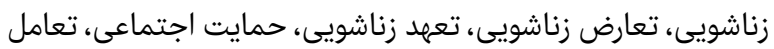

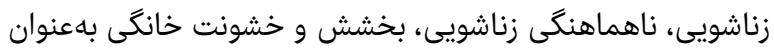

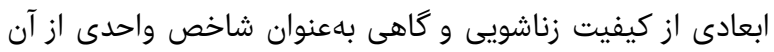

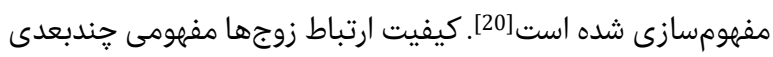

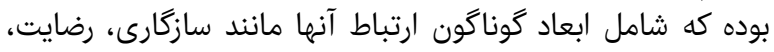

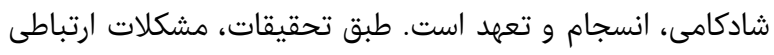

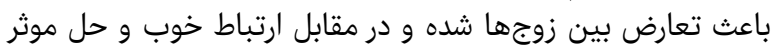

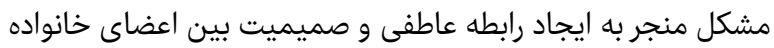

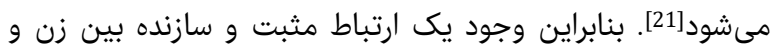

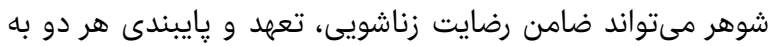

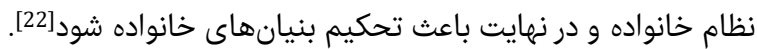

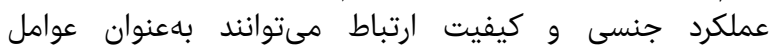

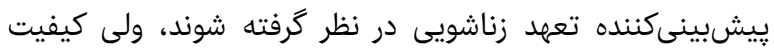

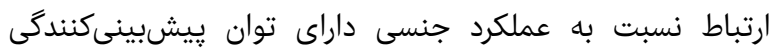

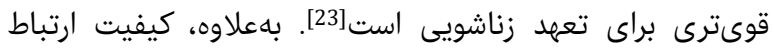

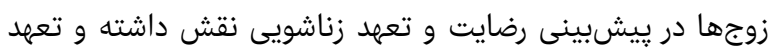

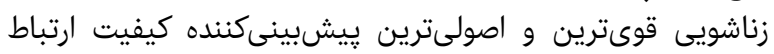
زوجها است [17, زئ.

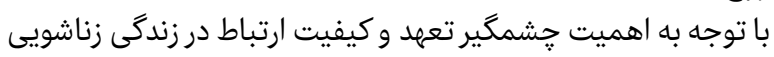

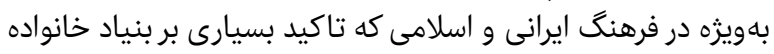

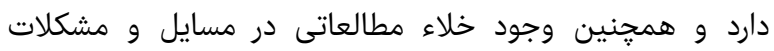

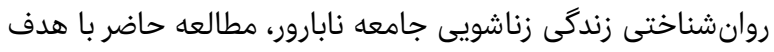

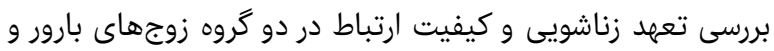

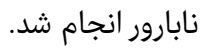

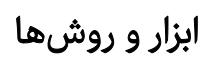
مطالعه توصيفى حاضر از نوع كوهورت است. جامعا آمارى آنارى شامل

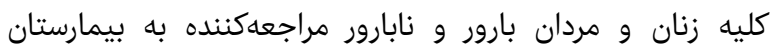

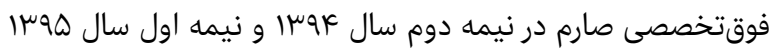

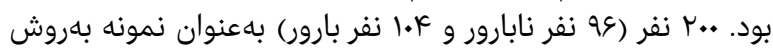

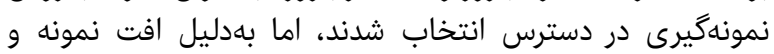

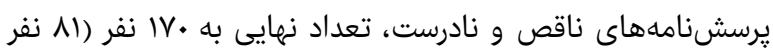

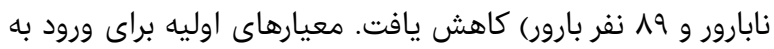

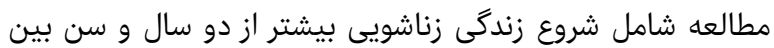

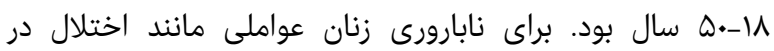

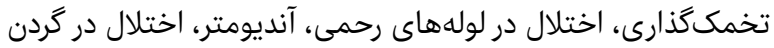

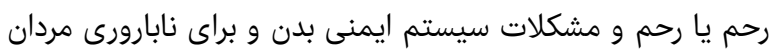




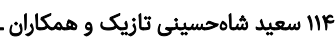

جدول r ب) ضرايب همبستكى بين تعهد زناشويى، كيفيت ارتباط و و خردهمقياسهاى آنها در زوجهاى بارور (19 نفر)

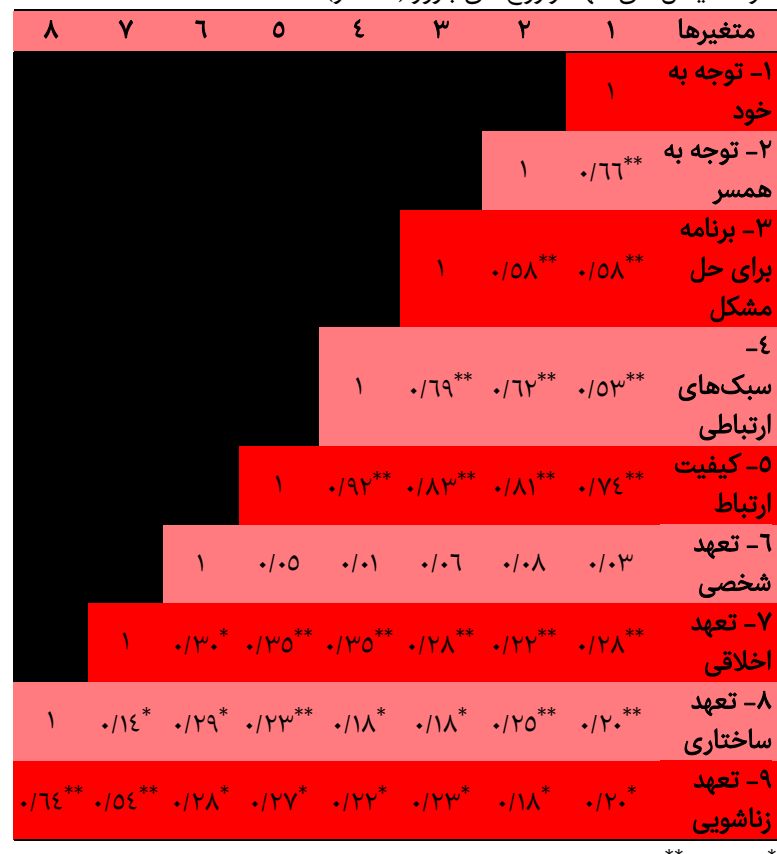

$\mathrm{p}<\cdot 1 \cdot 1^{* *} \mathrm{ep}<\bullet / \cdot 0^{*}$

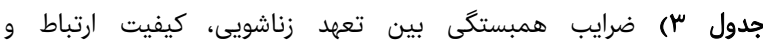

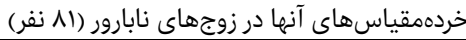

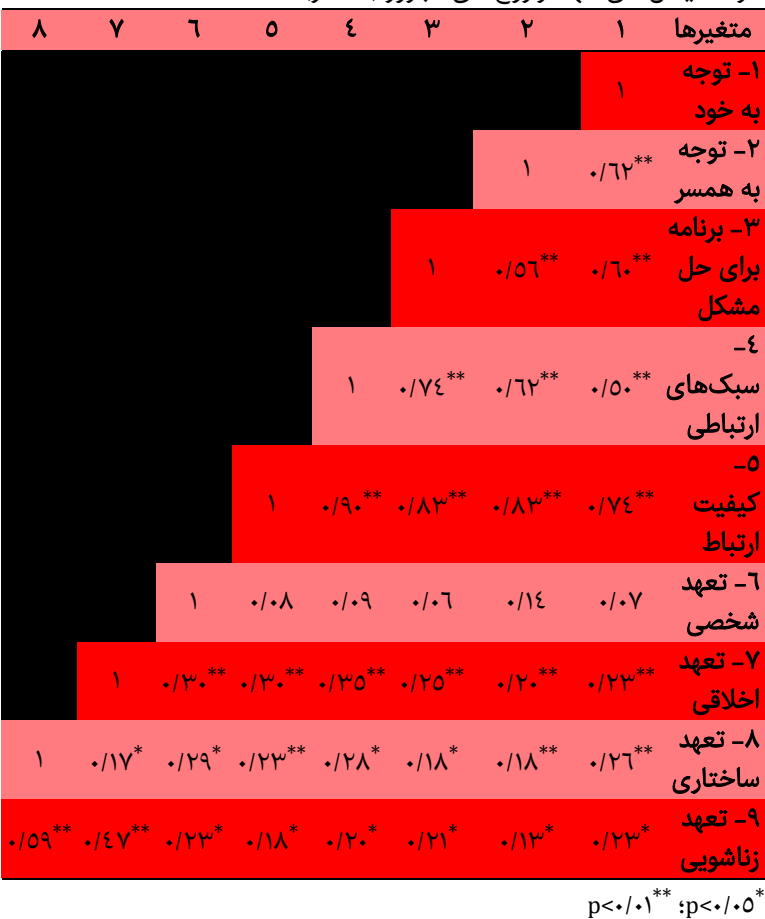

بحث

يافتهاى يزوهش حاضر با نتايج برخى مطالعات انجامشده در اين

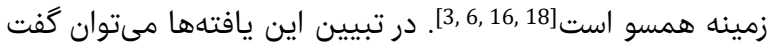

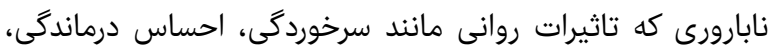

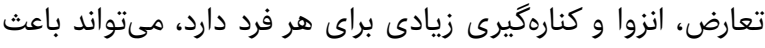
خدشهدارشدن روابط زناشويى شود. هر يك از مشكلات فردى في إنى ييش آمده ناشى ازنابارورى به اين دليل است كه همسر، خود را مقصر

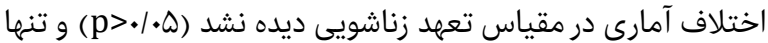

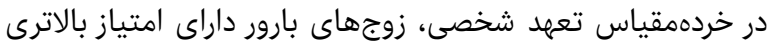

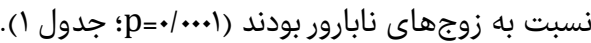

جدول (19) مقايسه ميانگين آمارى نمرات متغيرهاى تِروهش در دو گروه بارور

\begin{tabular}{|c|c|c|}
\hline سطح معنىدارى & نمرات & متغيرهاى يزوهش \\
\hline \multirow{4}{*}{$.1 . r q$} & & • كيفيت ارتباط زوجها \\
\hline & & توجه به خود \\
\hline & $19 / 19 \pm r / 97$ & كروه بارور \\
\hline & $\mid \Lambda / \cdot V \pm \varepsilon / \Lambda \Lambda$ & كروه نابارور \\
\hline \multirow{3}{*}{$.1 .0 \varepsilon$} & & توجه به همسر \\
\hline & $\mathrm{rN} / \mathrm{QV} \pm \mathrm{r} / \mathrm{QO}$ & كروه بارور \\
\hline & $r V / 7 / \pm 0 / \wedge V$ & گروه نابارور \\
\hline \multirow{3}{*}{. } & & برنامه براى حل مشكل \\
\hline & $r \cdot 1 \cdot\urcorner \pm \varepsilon / V\urcorner$ & كروه بارور \\
\hline & IN/ $\varepsilon \varepsilon \pm 0 / R r$ & كروه نابارور \\
\hline \multirow{3}{*}{$.1 \cdot \varepsilon 0$} & & سبكهاى ارتباطى \\
\hline & $0 \varepsilon / / V \pm \wedge / 90$ & كروه بارور \\
\hline & $01 / \cdot r \pm 1 Y / 9$. & گروه نابارور \\
\hline \multirow{3}{*}{.1 .14} & & \\
\hline & $\mid T r / V \varepsilon \pm I V / \cdot 1$ & كروه بارور \\
\hline & $110 / 17 \pm r \varepsilon / 1 \mathrm{~V}$ & كروه نابارور \\
\hline \multirow{4}{*}{.$|\ldots|$} & & • تعهد زناشويى \\
\hline & & تعهد شخصى \\
\hline & $0 T / \mu \Lambda \pm \mu / 0 \Lambda$ & گروه بارور \\
\hline & $\mu \wedge / \varepsilon \varepsilon \pm \mu / \Lambda \mid$ & كروه نابارور \\
\hline \multirow{3}{*}{. $17 \mu \varepsilon$} & & تعهد اخلاقى \\
\hline & $\mu N / r \cdot \pm \mu / \mu /$ & كروه بارور \\
\hline & 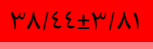 & گروه نابارور \\
\hline \multirow{3}{*}{.101} & & تعهد ساختارى \\
\hline & $\mu q / \varepsilon \varepsilon \pm \mu / \wedge r$ & كروه بارور \\
\hline & $r q / \cdot \varepsilon \pm \varepsilon / V r$ & گروه نابارور \\
\hline \multirow{3}{*}{$\cdot|V \varepsilon|$} & & \\
\hline & $\mid r \varepsilon / \cdot V \pm 0 / r \varepsilon$ & كروه بارور \\
\hline & $|\mu \mu / \Lambda \cdot \pm 7 / \mu|$ & كروه نابارور \\
\hline
\end{tabular}

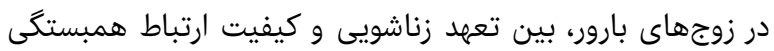

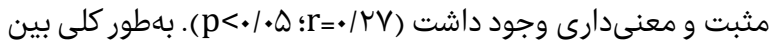

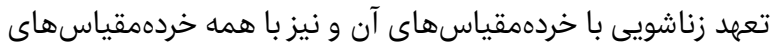

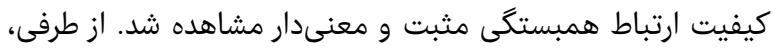

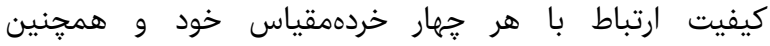

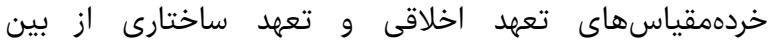

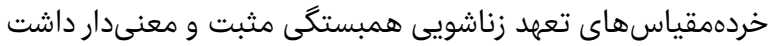

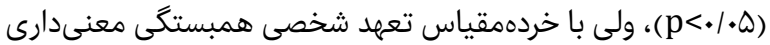

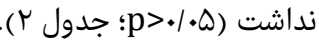

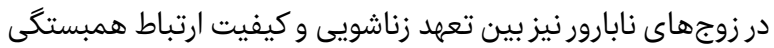

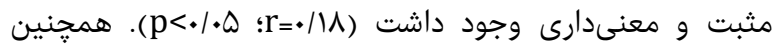

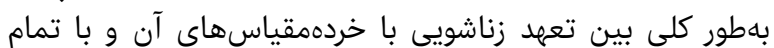

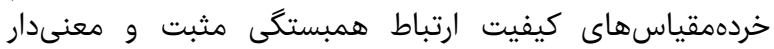

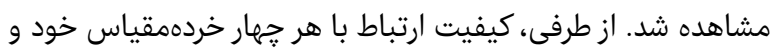

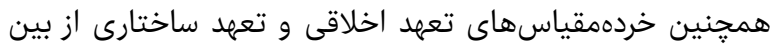

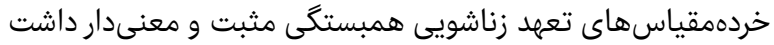

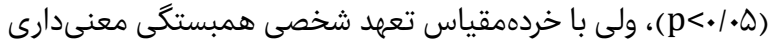

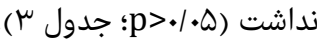




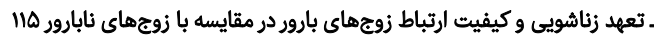

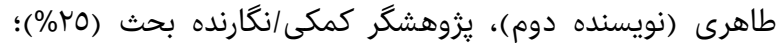

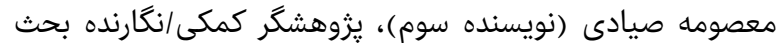

منابع مالى: اين مقاله مستخرج از طرح شماره بيمارستان فوقتخصى مالين مقاله مارورى و نابارورى صارم است.

منابع

1- Moura-Ramos M, Gameiro S, Soares I, Santos TA, Canavarro MC. Psychosocial adjustment in infertility: A comparison study of infertile couples, couples undergoing assisted reproductive technologies and presumed fertile couples. Psicologia, Saúde e Doenças. 2010;11(2):299. 319.

2- Peterson BD, Newton CR, Rosen KH. Examining congruence between partners' perceived infertilityrelated stress and its relationship to marital adjustment and depression in infertile couples. Fam process. 2003;42(1):59-70.

3- Nichols M. Lesbian sexuality/female sexuality: Rethinking 'lesbian bed death'. Sex Relatsh Ther. 2004;19(4):363-71.

4- Sherrod RA. Understanding the emotional aspects of infertility: Implications for nursing practice. J Psychosoc Nurs Ment Health Serv. 2004;42(3):40-7.

5- Behdani F, Erfanian M, Hebrani P, Hojat SK. Investigation of the prevalence of depression and factors affecting it in infertile women admitted in Mashhad's Montaseryeh infertility clinic. J Fundam Ment Health. 2004;6(23-24):141-6. [Persian]

6- Drosdzol A, Skrzypulec V. Evaluation of marital and sexual interactions of Polish infertile couples. J Sex Med. 2009;6(12):3335-46.

7- World Health Organization. Current practices and controversies in assisted reproduction [Internet]. Vayena E, Rowe PJ, Griffin PD, editors. Geneva: World Health Organization; 2002 [cited 2015 Sep 18]. Available from: http://www.who.int/reproductivehealth/publications/i nfertility/9241590300/en/

8- Shahsiah M, Bahrami F, Mohebi S. On the relationship between sexual satisfaction and marital commitment among couples in Shahreza City, central part of Iran. J Fundam Ment Health. 2009;11(3):233-8. [Persian]

9- Weeks G, Treat S. Couples in treatment. Abingdon-onThames: Routledge; 2013.

10- Lambert NM, Dollahite DC. The threefold cord: Marital commitment in religious couples. J Fam Issues. 2008;29(5):592-614.

11- Johnson MP, Caughlin JP, Huston TL. The tripartite nature of marital commitment: Personal, moral, and structural reasons to stay married. J Marriage Fam. 1999;61(1):160-77.

12- Abbasi Molid $\mathrm{H}$. The effectiveness of educating reality therapy on couples' marital commitment in Khomeynishahr county [Dissertation]. Isfahan: University of Isfahan; 2009. [Persian]

13- Amato PR. Reconciling divergent perspectives: Judith Wallerstein, quantitative family research, and children of divorce. Fam Relat. 2003;52(4):332-9.

14- Peterson BD, Newton CR, Rosen KH, Skaggs G. Gender differences in how men and women who are referred for IVF cope with infertility stress. Hum Reprod. 2006;21(9):2443-9.

15- Nichols MP, Guerin PJ, Chabot DR. Family therapy: Concepts and methods. New York: Gardner Press; 1984.
اين شرايط مىداند و اين امر باعث ناميدى و توجه كمتر به زندگى امثى

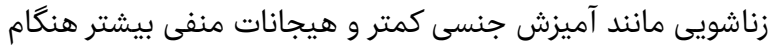

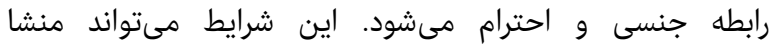

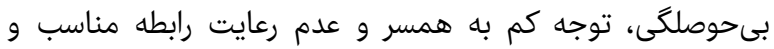

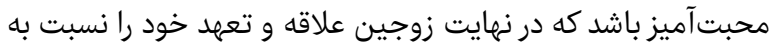

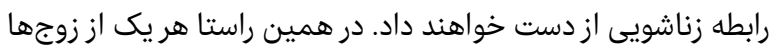

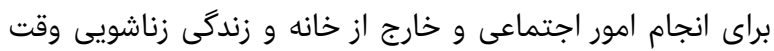

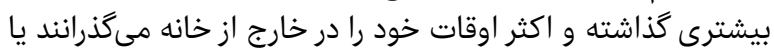

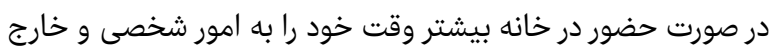

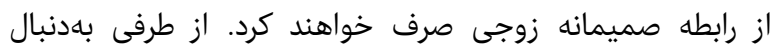

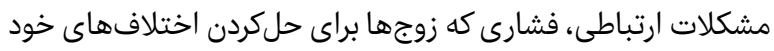

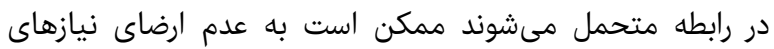

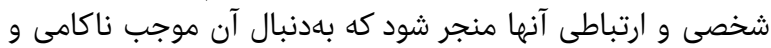

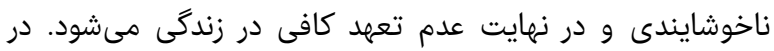

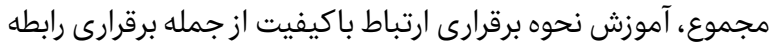

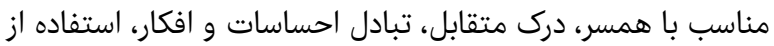

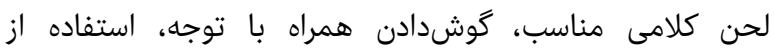

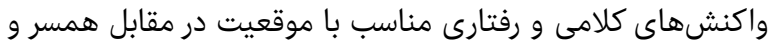

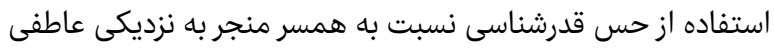
و بروز صميميت خواهد شد كه اين امر مشكلات ناشى از از نابارورى

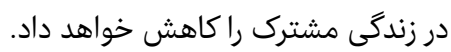

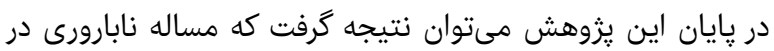

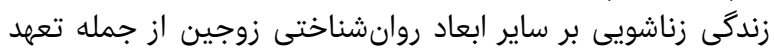

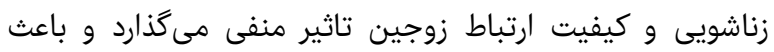

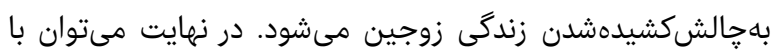

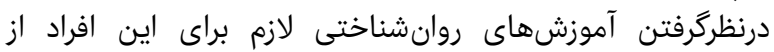
ييامدهاى ناخوشايند آن جلوكيرى نمون آنمود.

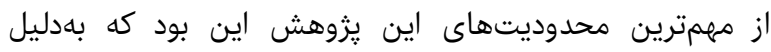

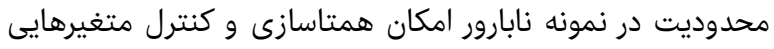

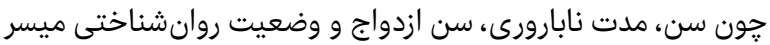

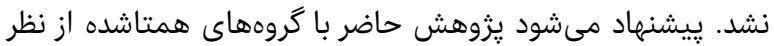

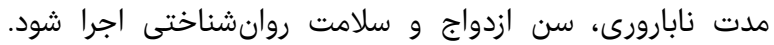

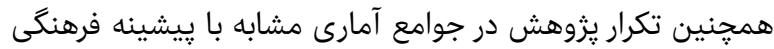

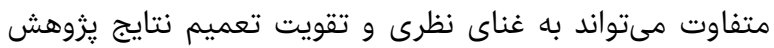

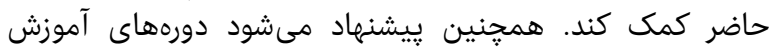

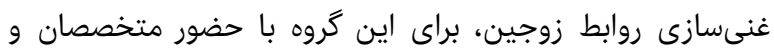
مشاوران حوزه خانواده بركزار شود.

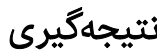

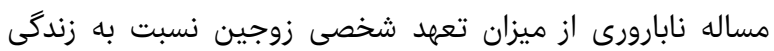

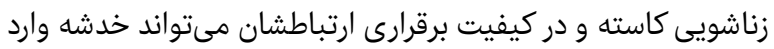

تشكر و قدردانى: از جناب آقاى دكتر غلامرضا حاجتى (استاديار

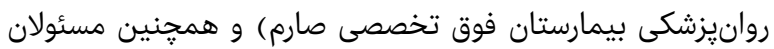

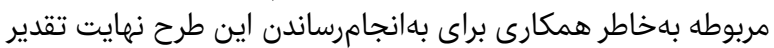

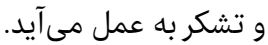
تاييديه اخلاقى: قبل از شروع كار از نويسندكان رضايت شفاهى كسب شد.

تعارض منافع: هيج گونه تعارض منافعى وجود ندارد.

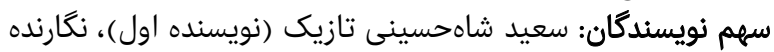

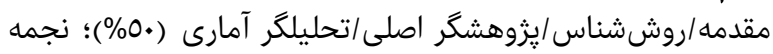


sexual function scale (MSFS). Biannu J Appl Couns. 2014;4(1):87-104. [Persian]

24- Litzinger S, Gordon KC. Exploring relationships among communication, sexual satisfaction, and marital satisfaction. J Sex Marital Ther. 2005;31(5):409-24.

25- Ghanbari Hashemabadi B, Hatami Varzaneh A, Esmaieli M, Farahbakhsh K. On the relationship among parenting styles, attachment styles and marital commitment in married female students of Allameh Tabatabai University. J Woman. 2011;2(7):39-60. [Persian]

26- Adams JM, Jones WH. The conceptualization of marital commitment: An integrative analysis. J Personal Soc Psychol. 1997;72(5):1177-96.

27- Reynolds J, Mansfield P. The effect of changing attitudes to marriage on its stability. In: Simons J, editor. High divorce rates: The state of the evidence on reasons and remedies, reviews of evidence on the causes of marital breakdown and the effectiveness of policies and services intended to reduce its incidence. $1^{\text {st }}$ Volume. London: Lord Chancellor's Department; 1999. pp. 1-38. 28- Khoshkam S, Ahmadi SA, Abedi MR. The effect of couple's relationship training course in the improvement of the relationship of the couples of Isfahan. J Res Couns. 2008;6(24):123-36. [Persian].
1119 سعيد شاهسينى تازيك و همكاران

16- Mosko JE. Commitment and attachment dimensions: Contributions to adult attachment development [Dissertation]. West Lafayette IN: Purdue University; 2009.

17- Clements R, Swensen CH. Commitment to one's spouse as a predictor of marital quality among older couples. Curr Psychol. 2000;19(2):110-9.

18- Amani A, Behzad D. The effectiveness of schematherapy on promoting marital commitment and couples' self-esteem. Couns Res. 2012;11(41):117-33. [Persian]

19- Stanley SM, Markman HJ, Whitton SW. Communication, conflict, and commitment: Insights on the foundations of relationship success from a national survey. Fam Process. 2002;41(4):659-75.

20- Speroff L, Fritz MA, editors. Clinical gynecologic endocrinology and infertility. Philadelphia: Lippincott Williams \& Wilkins; 2005.

21- Yaghmaei F, Mohammadi S, Alavimajd H. Developing quality of life in infertile couples questionnaire and measuring its psychometric properties. J Reprod Infertil. 2009;10(2):137-43. [Persian]

22- Moulavinia MJ. Sexual and marital knowledge. Qom: Imame Asr; 2004. [Persian]

23- Farajnia S, Hosseinian S, Shahidi S, Sadeghi MS. Codifying and examine psychometrics properties of marital 